Article

\title{
Digital Innovation Hubs as a Tool for Boosting Biomass Valorisation in Regional Bioeconomies: Andalusian and South-East Irish Case Studies
}

\author{
Marta Macias Aragonés ${ }^{1, *}$, Gloria de la Viña Nieto ${ }^{1}$, María Nieto Fajardo ${ }^{1}$, \\ David Páez Rodríguez ${ }^{1}$, James Gaffey ${ }^{2}$, Jennifer Attard ${ }^{2}$, , Helena McMahon ${ }^{2}$, Pat Doody ${ }^{3}$, \\ Judit Anda Ugarte ${ }^{4}, \mathrm{M}^{\mathrm{a}}$ Natividad Pérez-Camacho ${ }^{5}, \mathrm{M}^{\text {a }}$ Sol Cuenca Martín ${ }^{5}$, \\ Antonio José Giráldez Morales ${ }^{4}$ and Filippo Giancarlo Martinelli ${ }^{6}$ [D \\ 1 Fundación Corporación Tecnológica de Andalucía (CTA), 41092 Sevilla, Spain; \\ gloria.vina@corporaciontecnologica.com (G.d.l.V.N.); maria.nieto@corporaciontecnologica.com (M.N.F.); \\ david.paez@corporaciontecnologica.com (D.P.R.) \\ 2 Circular Bioeconomy Research Group, Shannon Applied Biotechnology Centre, Institute of Technology \\ Tralee, V92 CX88 Tralee, Ireland; James.Gaffey@staff.ittralee.ie (J.G.); jennifer.attard@staff.ittralee.ie (J.A.); \\ helena.mcmahon@staff.ittralee.ie (H.M.) \\ 3 Intelligent Mechatronics and RFID Centre, Institute of Technology, V92 CX88 Tralee, Ireland; \\ Pat.Doody@staff.ittralee.ie \\ 4 Consejería de Agricultura, Ganadería, Pesca y Desarrollo Sostenible, 41013 Sevilla, Spain; \\ judit.anda@juntadeandalucia.es (J.A.U.); ict-biochain.capder@juntadeandalucia.es (A.J.G.M.) \\ 5 Tragsatec Andalucía, 41016 Sevilla, Spain; mperez1@tragsa.es (M.N.P.-C.); mcuenca1@tragsa.es (M.S.C.M.) \\ 6 Irish Bioeconomy Foundation-National Bioeconomy Campus (Former Lisheen Mine), \\ E41 R622 Moyne, Ireland; Filippo@bioeconomyfoundation.com \\ * Correspondence: marta.macias@corporaciontecnologica.com; Tel.: +34-607-53-95-72
}

Received: 14 July 2020; Accepted: 9 October 2020; Published: 14 October 2020

\begin{abstract}
Regional bioeconomy development is directly linked to the availability and access to bioresources. Therefore, it is necessary to trigger opportunities for information and communications technologies (ICTs), the Internet of things (IoT) and Industry 4.0 solutions to increase the efficiency of high potential value biomass supply chains, improving this way the accessibility of bioresources. This study aims to present the results achieved through the development of Digital Innovation Hubs (DIHs) as a tool able to boost biomass valorisation, reshaping regional bioeconomy. The objective was to shape these DIHs and assess how stakeholders could be engaged and benefit from such initiatives. This has been attained through the design and implementation of DIHs in two case-study regions, Andalusia (Spain) and south-east Ireland (Ireland). The approaches and results for stakeholders' engagement, barrier mitigation, DIH structure and activities are presented. So far, more than 100 stakeholders have been engaged, more than 50 business opportunities have been promoted and a set of support services and events have been carried out. Main lessons learned are (1) about the relevance of understanding the needs of stakeholders, (2) impact is bigger when relevant regional industries (rather than academia/technology providers) discuss the technologies they have integrated and how these have improved efficiency or added value to their processes, and (3) about the importance of the communication plan and a well-formed DIH service definition.
\end{abstract}

Keywords: bioeconomy; ICT; supply chain; regional development; bioresources; stakeholder

\section{Introduction}

The biomass sector is strategically of high relevance for the economy in the European Union (EU) [1]. Biomass potential can be applied for its utilisation in food and feed, fibres, energy and 
fuels and materials. According to a recent study, if, by 2020,20\% of chemical products and oil-based products in Europe were replaced by bioproducts, 34 MMT (million metric tons) of biomass would be necessary. By 2030, 30\% would need at least 50 MMT while 48 MMT of biomass will be required to produce conventional biofuels, with up to $80 \mathrm{MMT}$ required to produce bio-based power and heat [2]. The current total EU biomass utilisation for food, feed and materials is 1100 MMT. Moreover, costs of feedstock are often higher in Europe than other jurisdictions due to regulations, climatic conditions and/or higher labour and operating costs [3]. These aspects make ensuring that the growing demand for biomass in Europe can be met by local supply challenging, especially from the sustainability point of view. Specifically, environmental aspects such as water scarcity and biodiversity, techno-economic aspects and social aspects (e.g., changing demographics and policy agendas) need to be considered. Addressing such a complex challenge requires, as well, to take into account the potential that information and communications technologies (ICTs) offer, but also the disruptive effects they can have on the current practices and habits of value chain actors, such as material extractors, material processors, manufacturers, retailers and users. These effects are related to changes in working procedures, behavioural aspects (e.g., communication channels) and the need for workers to learn about and adapt to these new technologies, among others. As Flak J. states [4], despite the general views about new technologies, which are seen as too expensive or rather complicated, needing not only an economic investment but also a newer skilled workforce, novel applications or tools are usually user-friendly. In fact, ICT providers are commonly willing to assist customers from the initial phase, installation and implementation and further corrective phases. Most solutions are nowadays price-competitive, adapted to the several needs and scales of operation. These types of benefits should be demanded in order to make a worthwhile investment. Moreover, in the biomass sector, different value chains characteristics exist in contrast to the ones in other industries which, consequently, opens a need for specific types of information and data management systems. There is the possibility of designing tools for a specific stage in a value chain. Flak J. has reviewed a long-list of technologies applicable to biomass value chains. For example, it can be of interest to monitor field conditions (soil humidity, $\mathrm{pH}$, rainfalls, wind), growth rate or ripeness to help farmers to maximize the production by, for instance, indicating a need for fertilisation or an optimal time for harvesting. Another option includes monitoring of the fleet while maintaining efficient customer communication to provide a high standard in the food value chain by tracking the location of the logistics and service management. Meanwhile, Flak, J. [4] states the existence of technologies to be applied throughout the entire supply chain. There are identification labels and environment sensors for humidity or temperature which can be utilised at any stage, assuring the quality and safety of a given agri-food product, while also boosting the reliability of storage or the logistics efficiency. There is another group consisting of information and communications technology (ICT) tools such as online databases and platforms. These ICT tools can be of crucial importance when forming new supply chains and/or optimising those already existing. For instance, they may include mapping data of the available and potential bioresources, websites with specific knowledge or its providers, contact medium for stakeholders and even online trading platforms. In fact, it is highlighted the numerous opportunities within the biomass supply chains of interest to stakeholders. The large volume and diverse nature of the data that those proposed technologies could manage, including both structured and non-structured data, calls for specific integration and management procedures to make the most of the new economic opportunities based on information, data and cognitive technologies. For instance, Vlachokostas, C. [5] identifies a need in the waste sector regarding the production of energy from waste biomass. As energy demand increasingly grows all over the world, non-reusable and non-recyclable waste streams are to be used in the correspondent value chain to produce energy, thus, fulfilling this demand. In this frame, Vlachokostas, C. [5] identifies that management of waste and energy supply chains, through interactions between technological solutions, can be provided in several pathways, varying depending on the chosen criteria and characteristics. Therefore, the ICT provides a path that closes the gap 
between producing efficient energy and most importantly, forms the basis for residents' empowerment and professionals' motivation to adopt eco-friendlier behavioural patterns.

Industry 4.0 approaches (the trend towards automation and data exchange in manufacturing technologies) could bring novel solutions that could contribute to unlocking European biomass potential, as well. Thus, it becomes of paramount importance to boost opportunities for the introduction of ICT to increase efficiencies, particularly advanced ICT like the Internet of things (IoT) or Industry 4.0 approaches, and to enhance the sustainability of biomass supply chains for the bio-based industry. IoT is a system of interrelated computing devices, mechanical and digital machines, objects, animals or people that are provided with unique identifiers and the ability to transfer data over a network without requiring human-to-human or human-to-computer interaction [6]. Since sustainable feedstock supply chains will permit the creation of sustainable bio-based value chains, biomass supply chain digitalization could serve as an engine for the economic development of rural areas.

With regards to ICT spread and digitisation, in 2016, the European Commission (EC) launched the first industry-related initiative of the Digital Single Market package [7]. Building on and complementing the various national initiatives for digitising industry, the Commission acted to trigger further investments in the digitisation of industry and support the creation of better framework conditions for the digital industrial revolution. One of the more important pillars of the Digitising European Industry [7] effort is the activity dedicated to developing a network of Digital Innovation Hubs (DIHs) [8]. Since 2016, a lot of DIHs have emerged, as well as EC initiatives such as the DIHs catalogue [9] and the DIH Academy [10]. In addition, $500 \mathrm{M€}$ from the H2020 budget (H2020 is the acronym for Horizon 2020, the EU funding programme for research and innovation) have been allocated between 2015 and 2020 to support the development of DIHs. It is the Commission's ambition that all companies should have a DIH within their region through which they should be able to access competences in order to digitise their organisations and their products and services [11]. For instance, a study has been developed in Italy in order to promote digitalisation in companies. The Italian study sheds light on the role of Italian DIHs in connecting small and medium enterprises (SMEs) to different knowledge sources. Its DIH system has a high number of industrial and artisan associations that act as coordinators. These actors are profoundly embedded in local territories and benefit from high levels of recipient trust. Some of the study's findings pointed out the importance of DIHs in facilitating the connections between the actors involved in the digital transformation process. Additionally, the study concludes stating that DIHs act as external enabling factors that foster connections with other companies and institutions fostering the development of innovation ecosystems [12].

ICT tools are already playing a role in forestry [13,14], and in the Swedish smart industry [15], and serve as examples for the bio-based industry supply chain. Woo, H. emphasises in his study that forest residue availability might be uncertain and there is a high risk of wrong decision making in the biomass supply chain [16], particularly, using electronic systems, such as geographic information system (GIS, a conceptualized framework that provides the ability to capture and analyze spatial and geographic data), Global Navigation Satellite System (GNSS, this refers to a constellation of satellites providing signals from space that transmit positioning and timing data to GNSS receivers; The receivers then use this data to determine location), and various kinds of sensors related to forest harvesting. The contributions of these tools to forest operation are wide and various. One of the most important applications was integrating ICT and GPS/GNSS on-board systems on modern forest machines. This allowed one to ensure multiple benefits to the forest operation field [17]. In addition, UAS (Unmanned Aerial Systems) technology has been introduced to measure biomass availability with reduced cost and time. Given the rising public awareness of bioenergy, a precise biomass estimation tool to support biomass industries is needed to make the most efficient use of biomass resources [16]. The adoption of this kind of technology through the development of DIHs and how this relates to Smart Specialisation Strategies (S3) in European regions has been assessed by the Joint Research Centre (JRC), the European Commission's science and knowledge service. This assessment points out that there are synergetic place-based relationships of DIHs and S3, with DIHs being the policy outcome of an S3 process or an active actor participating in S3 entrepreneurial 
discovery processes and implementing parts of S3 [18]. It can also be concluded that the use of DIHs as actors or initiatives can support digitalisation and the development of the surrounding innovation ecosystems in concrete territorial contexts [19].

Within this context, the purpose of the work presented herein is to develop a DIH as a tool for boosting biomass valorisation in a regional bioeconomy through the identification of feasible opportunities for ICT to improve the efficiency and sustainability of supply chains, enabling this way the regional cooperation between biomass suppliers and technology providers. The DIH covers several supply chains handling different kinds of biomass coming from multiple bio-resources so the impact can be of significance for the bio-based industries, and the full bio-based sector existing in European regions. The general structure that follows a DIH focused on boosting biomass valorisation includes competence centres as the core organisations in the DIH general structure, interacting with the rest of stakeholders. Competence centres can be universities, research and technology organisations (RTOs) or incubators. These competence centres are used as the main knowledge transfer vectors from which other stakeholders in the DIH will benefit. Other stakeholders considered in the DIH general structure can be from the primary sector as farmers and agri-business; from the secondary sector as industry advisors, consultants, ICT developers or start-ups or from the tertiary sector as governments, investors or innovation brokers.

As explained above, a DIH can play a role both horizontally, by providing digitalisation support to all sectors, and vertically, by leading or taking part in processes of mobilising stakeholders towards innovation. In this sense, a DIH can act as a policy outcome of an S3 process, or an actor implementing parts of S3 [18]. In this case, the main aim of the work is to act vertically, by bringing together leading experts and support networks in order to develop DIHs to examine opportunities for ICT, IoT and Industry 4.0 to act horizontally, i.e., in this case, to increase the efficiency of high potential biomass supply chains. The geographical scope for this study was south-east Ireland (Ireland) and Andalusia (Spain), which have served as testbed locations (case studies) for the development of DIHs for biomass mobilisation. In 2016, the EU selected six "model demonstrator regions" (MDRs) in Europe to lead the way towards sustainable chemical production [20]. The selected case studies are two of these high potential model demonstrator regions. During the work that was conducted, the hubs provided access to the best knowledge, information and technology to promote opportunities for ICT, IoT and Industry 4.0 to be integrated into high potential biomass value chains, supporting this way, on the one hand, the development of the EU bioeconomy by facilitating greater availability of competitively priced and sustainable biomass, and on the other hand, the creation of new cross-sector interconnections in bio-based economy clusters. The DIH involving biomass and ICT suppliers also contributes to the reduction of biomass losses and costs associated with feedstock supply logistics compared with similar existing benchmark supply chains. The resulting introduction of ICT in the biomass feedstock supply chain for the bio-based industry in other regions contributes to the sustainability and efficiency in the long term along all bioeconomy regions, highlighting the importance of DIH formation as creating regional structures for the development of the bioeconomy through cooperation and mobilisation of the main actors at a regional level which can be replicated in other regions.

It can be considered that DIHs could be pointed out as a new collaboration model that triggers the development of open innovation ecosystems by the way they are defined and implemented (following a multi-stakeholder, multi-sectoral approach and having a competence centre as a link to innovation, promoting this way new knowledge flows).

Finally, it is worth mentioning other approaches that can be found in the literature regarding how to boost transformation through digitalisation using an open innovation approach. For example, the dedicated innovation systems discussed by Pyka [21] were developed as a tool to support the transformation towards sustainability by creating income opportunities and employment in the knowledge-based digital bioeconomy. Other knowledge areas such as the ceramics sector and its digital transformation have also been addressed, in this case from the Industry 4.0 perspective [22]. 


\section{Materials and Methods}

The framework for this study is the European project ICT-BIOCHAIN (ICT Tools in Efficient Biomass Supply Chains for Sustainable Chemical Production), funded by the Bio-Based Industries Joint Undertaking under the European Union's Horizon 2020 research and innovation programme with grant agreement No 792221. During the lifetime of the ICT-BIOCHAIN project, the following reports have been produced: "Assessment of current ICT, IoT and Industry 4.0 Solutions in European biomass utilisation" [23] and a "Validation report of the platform prototype per each region-specific data model" [24]. This information, together with a regional baseline definition exercise [25], DIH knowledge transfer events, demonstration days and business opportunities, has been used when developing and dynamizing the DIHs. All this information by means of public deliverables or project materials (videos and project platform) can be found on the project website [26].

Herein, a summary of the main aspects for DIH implementation for each region (south-east Ireland and Andalusia) will be described while differences will be highlighted for a comprehensive understanding of the main steps and methods.

In order to secure a process for the establishment of two pilot Digital Innovation Hubs for biomass supply chain development, several objectives were set as follows:

(1) To identify the baseline for the implementation of the DIH, determining the current regional situation of ICT, IoT and Industry 4.0 adoption in biomass value chains and potential barriers.

(2) To identify and engage main stakeholders to be involved in the DIHs in each region as this will allow for the development of a network of stakeholders covering all essential aspects of a DIH.

(3) To articulate and set-up the structure of DIHs in the selected MDR; the structure definition of DIH in each region is performed by establishing a hub manager, steering committee and competence centre.

(4) To prepare a set of documents and communication tools that will support further day-to-day activities of the DIH.

(5) To enable extensive knowledge transfer on ICT, IoT and Industry 4.0 within model demonstrator regions: transfer best practice technologies and offer practical demonstrations of relevant ICT, IoT and Industry 4.0 opportunities for biomass mobilisation through a designated demonstration day.

(6) To identify high potential opportunities based around specific ICT, IoT and Industry 4.0 functions and develop innovation partnerships around these opportunities to turn these into investment-ready opportunities.

The process for the implementation of a regional DIH is shown in Figure 1, covering the six objectives summarised above. Now each stage of the process methodology will be explained, and each objective fulfilled. In this methodology, the term "stakeholders" refers to the people from society, industry, academia or administration involved in the hub, benefiting from its activity.

First, regional baselines were defined in both regions of study (south-east Ireland and Andalusia). The regional baseline definitions consisted of the assessment of both regional contexts in terms of mapping the utilisation of ICT, IoT and Industry 4.0 tools in biomass supply chains. This allowed the definition of the starting point for the DIHs' implementation. This work is published partially [4]. Once this was done, barriers towards DIH development were identified. The aim was to design the DIH structure, related activities and the stakeholders' engagement plan so these barriers could be addressed. This was carried out by a working group composed of a regional organization (central node for DIH development) and a regional facilitator (in charge of stakeholder outreach and operational capacity). In addition, several meetings between the case study regions' representatives were held. This helped the exchange of experiences and knowledge sharing as well as the identification of common barriers. 


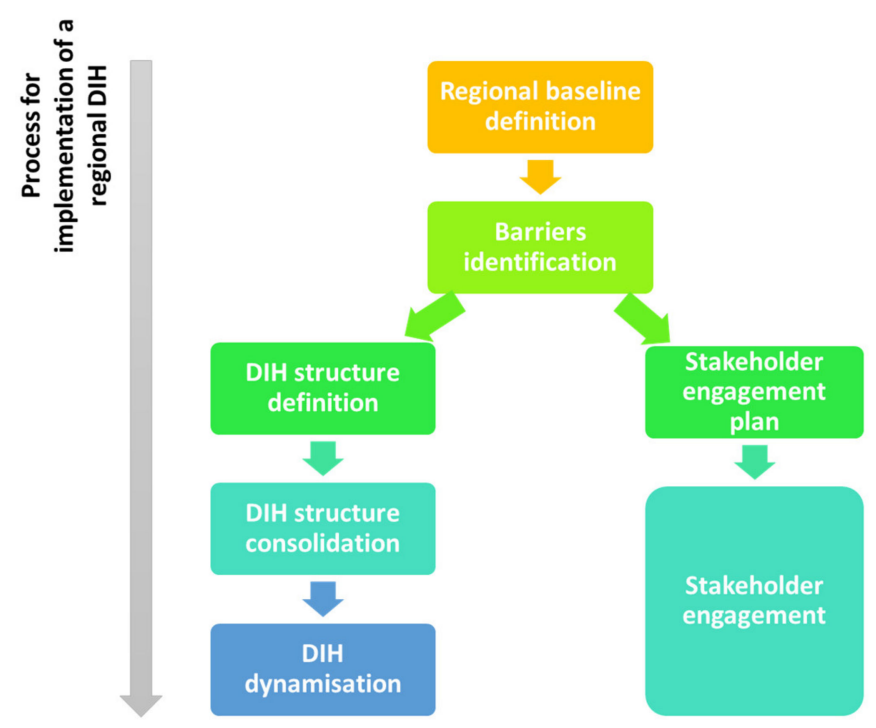

Figure 1. Process methodology for implementation of a regional DIH.

The articulation of both the DIH structures and the stakeholder engagement plan definition were conducted in parallel. The DIH structures were designed to allow easy DIH management and operation while involving the required knowledge and providing direct contact with stakeholders. The main components of each DIH are a hub manager assisted by a competence centre and a steering committee with three bioresource advisors (one per value chain of study in each region) and one technology and one business advisor. The designed structure can be observed in Figure 2 as follows.

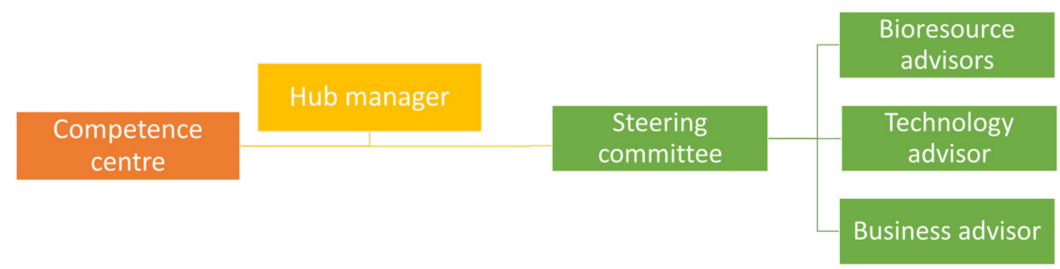

Figure 2. DIH general structure.

Stakeholder involvement was performed by the development of a network database containing relevant stakeholders within the two Digital Innovation Hubs for sustainable biomass mobilisation. The network included regional ICT developers, technology providers and all stakeholders from the biomass supply chain. Relevant actors such as public bodies, academia, platforms and associations were included. In fact, this network was constantly enlarged during the project lifetime by participants coming from the various events being offered.

Once participants from the network were identified, communications were maintained in order to explain to them the concept of a Digital Innovation Hub, the benefits that participating in such an initiative could have for them, etc. Communication and documentation were customised to each type of stakeholder, particularising the key messages to be delivered.

Different channels were employed such as emails, phone calls, face to face or online meetings, focus groups and thematic workshops. This helped to maximise the chances for stakeholder commitment.

After the structure of the DIH and communications to stakeholders were defined, actions to accomplish stakeholder engagement started while in the meantime the DIH was being consolidated (recruitment and confirmation of the participation of advisors and relevant roles). Once the consolidation phase was over, the DIHs' dynamisation was carried out: enabling extensive knowledge transfer on ICT, IoT and Industry 4.0 within model demonstrator regions by launching events in both MDRs, transferring best-practice technologies. Practical demonstrations of relevant ICT, IoT and Industry 4.0 
opportunities for biomass mobilisation through a knowledge transfer and designated demonstration days were offered, concluded with investment days where financial support was available to finalise the partnerships among biomass and technology providers. Activities foreseen for DIHs' dynamisation can be found in Figure 3 as described above and which finally covers objectives 5 and 6 .

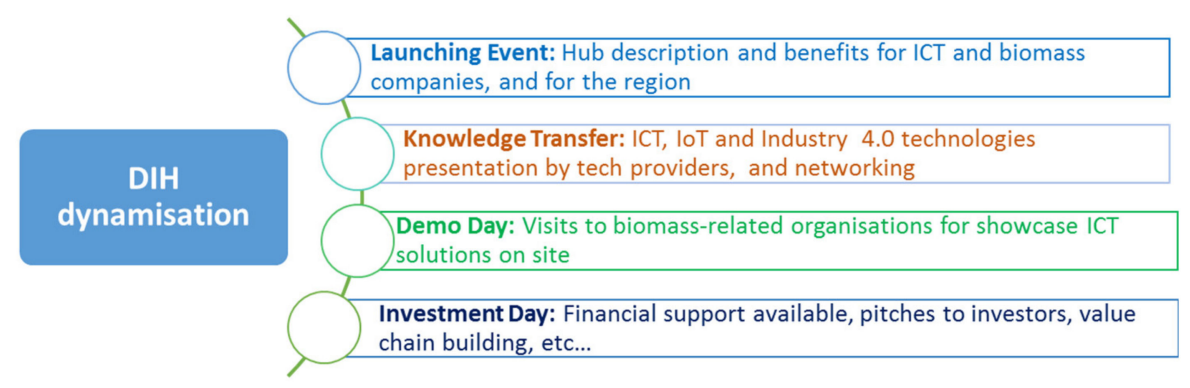

Figure 3. Events foreseen for DIHs' dynamisation. IoT-Internet of things (IoT).

Regarding these four events, the same approach was followed in both regions. Events shaping was done using an event proposal template to gather all relevant information about resources to be used, agenda, targeted stakeholders and potential risks to be considered. For each event, a satisfaction survey (feedback form) was prepared and provided to the participants, allowing information retrieval for further events shaping and for business opportunities spotting. In addition, at each event, all attendees were asked to complete a questionnaire about ICT adoption status to allow for the identification of stakeholders that might need advice on the best technologies available for them.

\section{Results}

As explained in the methodology section, several results have been produced during the lifetime of the ICT-BIOCHAN project which will be exposed as follows in this order: (1) baseline definition of both regions for the implementation of the DIHs, determining the current regional situation of ICT, IoT and Industry 4.0 adoption in biomass value chains; (2) potential barriers to be encountered when implementing a DIH; (3) stakeholder engagement plan; (4) DIH structure definition; (5) DIH activities and events; and (6) establishment of value chain coalitions to foster regional development.

\subsection{Baseline Definition}

The baseline definition was considered the starting point for the development and implementation of ICT-BIOCHAIN activities regarding the DIH in both regions, south-east Ireland and Andalusia. The information regarding the regional situation of ICT, IoT and Industry 4.0 adoption in biomass value chains as published by J. Flak, 2020 [4] and the information about the regions which will allow a comprehensive understanding of this article were compiled. An overview of the two case-study regions is provided in the following paragraphs.

The south-east Ireland region is centred on the site of the former lead/zinc mine in Lisheen. Recently, the Lisheen site has undergone surface and underground rehabilitation being reconverted to Ireland's National Bioeconomy campus located at the heart of Ireland's agri-food sector. The agri-food sector in Ireland is responsible for significant employment, producing substantial volumes of outputs with formidable financial value, and playing a role in feeding an ever-growing global population. Main opportunities have been found in the agri-food and forestry value chains. The residues which arise from their processing include whey residues from cheese or casein production; dairy fat from milk processing; spent mushroom compost and stalk cut-offs from mushroom production; various sludges from wastewater treatment; food crop residues from apple, potato, and other food processing; lignocellulose from the wood processing sector; spent grains from the brewing and distilling industry; animal by-product from meat processing and manures from the livestock sector. The biomass potential identified in Ireland as a whole amount is $>2$ MMT (million metric tons) of tillage crops; 1.2 MMT of 
straw; 37 MMT of livestock waste; 550,000 MT (metric tons) animal by-products; >100,000 MT spent mushroom compost; >160,000 MT brewers' grains and circa 1 MMT underutilized wood residues per year [27]. In the framework of the present study, three value chains were selected, namely, whey, horticulture and lignocellulose as the main focuses of the project and so the DIH was defined according to this selection.

Andalusia is in the south of Spain and has a unique bioeconomy potential since it features a large agricultural sector. Over $44.3 \%$ of its surface area and $8.4 \%$ of its workforce are dedicated to this sector [28], and Andalusia's agri-food industry is one of the main economic drivers of the region [29]. It is extended all over the Andalusian area and is widely present in rural areas. Waste products and oils, derived from the olive groves (pruning, mill leaf, olive pomace, olive marc and olive pit) are a large and attractive feedstock for new value chains. The fact that Andalusia is the major olive producer worldwide and olive oil bio-based industries are well developed could result in economies of scale or build on specific oil refining expertise which allow it to be more competitive than other European regions. Banias G. et al. [30] reviewed the environmental impacts dragged from the life cycle of olive oil. He stated that the use of chemical products (pesticides, fertilizers) cause significant burden to the environment since they are oil-friendly compounds and, for that reason, are easily detected in the oil of the olives. Moreover, the use of such products is also responsible for the pollution of groundwater and the erosion of soil. Large quantities of water are also required for irrigation purposes. More specifically, to produce $1 \mathrm{~L}$ of extra virgin olive oil, $433.6 \mathrm{~g}$ of fuel and $3900 \mathrm{~L}$ of water are consumed. For the cultivation of one acre of olive grove, $64.8 \mathrm{MJ}$ is required. Fertilizing and spreading the insecticides require $247 \mathrm{MJ}$ and $3317 \mathrm{MJ}$ per ton of olives, respectively. A medium-sized mill receives 10-20 tons of olives per day and produces 0.5 and $1.5 \mathrm{~m}^{3}$ olive mill wastewater per ton of olives. The water used either for washing the olives or before the centrifugation further increases the liquid wastes' production, which may reach $54 \mathrm{~L}$ of water for a litre of extra virgin olive oil produced. The production of olive oil also includes energy and fuel consumption. Specifically, $1493 \mathrm{~kJ}$ is consumed for each ton of processed olives and $158.2 \mathrm{~kg} \mathrm{CO}$ are emitted. The processes to reduce olive's bitter taste are most responsible for the increased emissions. Additionally concerning are packaging wastes impact and transport emissions [30]. Fruit and vegetables are important because of the high volumes of vegetable remains involved in intensive horticulture. For forest feedstocks, lignocellulosic value chains could be established towards paper, composites, polymers or chemicals. Furthermore, due to its sunny climate and intensity of solar irradiation (because of Andalusia's southern location), cost-effective algae cultures are a promising feedstock and a huge opportunity for high-quality proteins and bioactive compounds production [31]. The biomass potential identified in Andalusia includes more than 8 MMT of agricultural waste (of which over 2 MMT correspond to the olive oil industry and nearly 3 MMT to several cereals). There are also 12.1 MMT of livestock waste; around 6.3 MMT of industrial waste; just over 320,000 MT of forest biomass and 1.6 MMT of urban waste. In addition, Andalusia has a capacity of biofuel production of 1.3 MMT per year plus nearly $1800 \mathrm{MW}$ of thermal power and $>250 \mathrm{MW}$ of electric power from biomass and $>30 \mathrm{MW}$ from biogas [32]. In the framework of the present study, three value chains were selected, namely, olive and olive oil waste, horticulture waste and algae which were used as well for the definition of DIH components as explained in next section.

Regarding ICT, IoT and Industry 4.0, both regions have several solutions available in the market that aim to make farmers' work easier. These products are usually focused on retrieving data and handling them in order to make the most out of available information. This goes from traceability and information availability for the consumer/biomass buyer to integration of information with weather forecast and plagues information in order to reach cost- and resource-efficient planification and management of crops and farms. Nevertheless, there is no relevant outstanding solution related to biomass logistics, thus, demonstrating a clear gap towards the sector's full digitalization.

Concerning the past experiences with DIHs in each region, both have previously conducted several interesting initiatives that serve as foundations for the developed DIHs. In the case of south-east Ireland, the most relevant past initiatives are the Manufacturing Industry Digital Innovation Hub, 
Dingle Creativity and Innovation Hub, Smart Agri Hubs and Dublin Digital Hub Project [33]. As for Andalusia, these are Andalucía Agrotech DIH, Andalusian Circular Bioeconomy Cluster, Linares4.0, Knowledge City (DIH), OnGranada-Granada Plaza Tecnológica y Biotecnológica and National Pole of Digital Content, POLO [34].

\subsection{Barriers Identification}

In both cases, regions pointed out that demonstrating the relevance and benefits of getting involved in the DIH to the different bio-based industries and private sector, in general, is a main barrier. Another challenge identified is the geographic fragmentation of companies and technology providers that might be linked to the hub, which can make technology access or demonstration more difficult to achieve. A set of secondary barriers were also identified, grouped around stakeholder involvement (e.g., lack of motivation from biomass suppliers to improve their local supply chains, low stakeholder involvement and needs of industry/stakeholders not being met), information availability (accessing information on existing technologies/best practices, knowledge gap within companies and low data availability and specific applications to bioeconomy) and DIH regional definition (lack of regional focus, low coordination between value chain stakeholders, legal form for the DIH establishment, definition of DIH value proposition and lack of specific financial instruments).

Regional representatives worked further in order to delve into these barriers so mitigation actions could be better shaped. This was a collaborative process where both regions gathered all the information in the so-called Barriers Mitigation Toolbox (please see Figure 4). In this Barrier Mitigation Toolbox, information is broken down according to the following fields: barrier category, barrier definition, mitigation action and how to address barrier through hub design and activities.

Main barriers were grouped in the following categories: (1) information availability, (2) funding, (3) stakeholder engagement and (4) regional DIH definition. Information availability covered the lack of regional focus and knowledge gaps within companies. Funding category was related to the lack of specific financial instruments. Concerning stakeholder engagement, the main identified barrier was low stakeholder involvement. Finally, concerning the DIH regional definition, the legal form for the DIH establishment and the definition of the DIH value proposition were pointed out. Actions to tackle these challenges and barriers have been included in the risk mitigation toolbox, mostly related to the use of knowledge about the regional context and the closer link that this can provide when interacting with stakeholders.

\subsection{Stakeholder Engagement Plan}

In order to engage with stakeholders, insights on how to carry this out can be summarised as (1) conduct profile characterisation, as biomass, ICT or another type of related company; (2) list the benefits of joining a DIH in a customised way with a tailor-made communication approach; (3) keep in mind the existence of key messages when communicating with stakeholders with the aim to catch their attention and finally (4) understand the importance of the communication channel, the timing and the correct person to further expand the engagement. Figure 5 represents the four cornerstones of the developed stakeholder engagement plan as it has been explained.

As tailoring communication activities is of one of the main cornerstones, three groups of stakeholders were defined: (1) private companies that own, treat, trade or manage biomass; (2) private companies with ICT, IoT, or Industry 4.0 solutions and (3) other stakeholders that could be interested in the hub such as universities, public administration, NGOs (Non-Governmental Organizations), etc. Then, customised information about the benefits of joining the hub was produced. In parallel, key messages to be transmitted to stakeholders were defined, e.g., "The DIHs act as a one-stop shop offering access to competences, infrastructure, training, networking, etc." Contact through two communication channels was considered: emails and phone calls. Accordingly, an email template was created for each stakeholder profile. In addition, guidelines for phone calls were also produced, pointing out the key ideas to be explained depending on the stakeholder profile. 


\begin{tabular}{|c|c|c|c|c|}
\hline \begin{tabular}{|c|} 
Barrier \\
Category
\end{tabular} & Barrier & Definition & Mitigation Action & $\begin{array}{l}\text { How To Address Barrier Through Hub } \\
\text { Design And Activities }\end{array}$ \\
\hline 흘르를 & $\begin{array}{c}\text { Lack of } \\
\text { regional focus }\end{array}$ & $\begin{array}{l}\text { The information collated by } \\
\text { the hub is too general }\end{array}$ & $\begin{array}{c}\text { A focus of the project is to access regionally } \\
\text { available information on biomass and } \\
\text { bioresource availability to complement } \\
\text { scoping on technology availability }\end{array}$ & $\begin{array}{l}\text { Careful selection of relevant technologies } \\
\text { for knowledge exchange and } \\
\text { demonstration activities. Ensuring regional } \\
\text { relevance of technology to complement } \\
\text { feedstock scoping }\end{array}$ \\
\hline 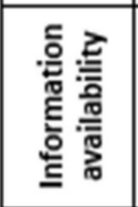 & $\begin{array}{l}\text { Knowledge } \\
\text { gap within } \\
\text { companies }\end{array}$ & $\begin{array}{l}\text { Agriculture is a very } \\
\text { traditional sector which } \\
\text { innovation promotion and } \\
\text { implementation is } \\
\text { complicated }\end{array}$ & $\begin{array}{l}\text { Potential gains due to innovations } \\
\text { should be clearly explained } \\
\text { Tailor-made communications will } \\
\text { be done }\end{array}$ & $\begin{array}{l}\text { Steering committee members as contact } \\
\text { points on specific areas of expertise }\end{array}$ \\
\hline 点 & $\begin{array}{c}\text { Lack of } \\
\text { specific } \\
\text { financial } \\
\text { instruments }\end{array}$ & $\begin{array}{c}\text { There are not existing tools for DIH establishment } \\
\text { in the regions. These structures should be built on } \\
\text { the basis of partners' contributions and a mix of } \\
\text { existing tools }\end{array}$ & $\begin{array}{l}\text { During DIHs' implementation in the MDRs a } \\
\text { detailed plan will be done to analyse } \\
\text { different options for initial funding }\end{array}$ & $\begin{array}{l}\text { Identify and engage with funding agencies, } \\
\text { venture capitalists, angel investors, } \\
\text { research funding bodies etc. Add someone } \\
\text { from business and investment community } \\
\text { to steering committee }\end{array}$ \\
\hline 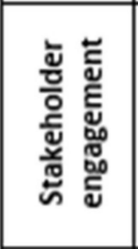 & \begin{tabular}{c|} 
Low \\
stakeholder \\
involvement
\end{tabular} & \begin{tabular}{|c|} 
Stakeholder participation in \\
project activities is low. A lot of SMEs and small \\
producers are family-owned businesses, with \\
pyramidal decision-making mechanisms that make \\
difficult the development of new cooperation \\
opportunities for technology transfer
\end{tabular} & \begin{tabular}{|c|} 
Case studies built already established \\
networks including bioeconomy, technology \\
and primary producers to bring knowledge \\
on bioeconomy and its intersection with ICT \\
to a broader audience. Active \\
communication, events, B2B meetings, etc.
\end{tabular} & $\begin{array}{l}\text { Direct and personal communication with } \\
\text { stakeholders on project and its } \\
\text { objectives/opportunities to partner } \\
\text { networks. Build on existing networks and } \\
\text { develop links with additional } \\
\text { national/regional initiatives in Bioeconomy }\end{array}$ \\
\hline 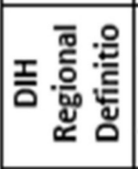 & $\begin{array}{c}\text { Legal form for } \\
\text { the DIH } \\
\text { establishment }\end{array}$ & $\begin{array}{c}\text { There are several strategies for the legal } \\
\text { establishment of the DIH. Hence, final strategy } \\
\text { must be carefully selected as it could limit the } \\
\text { dynamics of the DIH }\end{array}$ & $\begin{array}{c}\text { Deep analysis about the different options } \\
\text { and advice from specialised consultants will } \\
\text { be performed }\end{array}$ & $\begin{array}{c}\text { As this is the establishment of a pilot hub, } \\
\text { need to consider the necessity for legal } \\
\text { advice on implementation }\end{array}$ \\
\hline 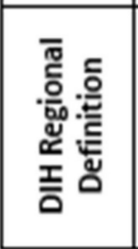 & $\begin{array}{l}\text { Definition of } \\
\text { DIH } \\
\text { value } \\
\text { proposition }\end{array}$ & $\begin{array}{l}\text { A wrong definition of the value proposition can } \\
\text { affect the future development of the DIH. A clear } \\
\text { offer to the partners to meet their needs should be } \\
\text { done, in order to ensure long-term viability. Service } \\
\text { level and funding scheme require a fine tuned } \\
\text { description during strategic DIH development }\end{array}$ & $\begin{array}{l}\text { Questions about which services the } \\
\text { stakeholders expect to receive are to be } \\
\text { included in the feedback forms. This will } \\
\text { allow further DIHs' shaping }\end{array}$ & $\begin{array}{l}\text { In terms of value proposition, the hub is a } \\
\text { one-stop shop for information on regional } \\
\text { feedstock availability, technologies for use } \\
\text { within regional supply chains, networking } \\
\text { development and knowledge exchange }\end{array}$ \\
\hline
\end{tabular}

Figure 4. Barriers Mitigation Toolbox. 


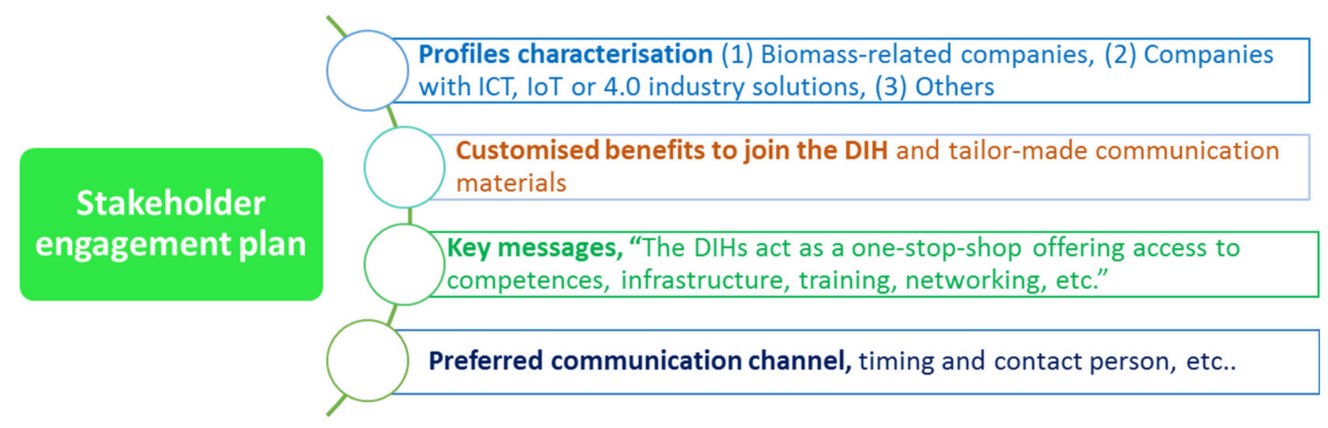

Figure 5. Key aspects of the stakeholder engagement plan.

\subsection{DIH Structure}

The developed DIHs were embedded, in both case studies, in the already existing regional ecosystems to maximise their impact. ICT-BIOCHAIN was the name selected for the DIHs in both regions as both specialised DIHs have been formed under the project lifetime and technical support.

In the case of Andalusia, the regional perspective considered previous territory-based initiatives for building the DIH. It also ensured its scalability by following an umbrella structure where ICT-BIOCHAIN DIH is embedded in the agro-tech DIH called Andalucía Agrotech DIH, making room for other DIHs to join and having Andalucía Agrotech DIH as the cornerstone of the regional digitalization efforts. Andalucía Agrotech DIH and ICT-BIOCHAIN DIH interact with the Andalusian Circular Bioeconomy Cluster, as it is an excellent pool of stakeholders, providing a system approach as well as a base for influencing regional policies and initiatives. Please see Figure 6.

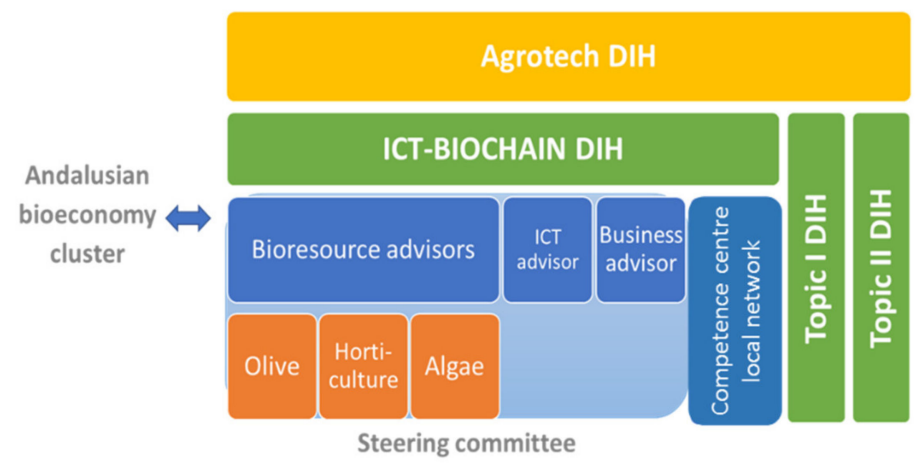

Figure 6. Andalusian DIH structure and how it integrates with the already existing Agrotech DIH.

The set-up of the Irish DIH was based on the model provided by the European Commission as depicted in Figure 7. Ireland's DIH was centred at the National Bioeconomy Campus at Lisheen, County Tipperary. The hub outreaches to the significant bioeconomy networks developed through previous regional and EU projects. As previously outlined in this study, several regional DIHs are being established in different sectors. These hubs, along with the various technology centres of excellence and SME technology providers form a key outreach audience for the hub and bring expertise in a variety of technology innovations. The already existing networks in the region are part of the DIH, including Smart-Agri-Hubs, The Dingle Hub and Irish Manufacturing Research (IMR).

Furthermore, when developing the DIH structure, both Andalusian and Irish partners were asked about their expectations and ideas regarding the different roles to be considered. The key idea driving DIH structure design was how to allow easy DIH management and operation while involving the required knowledge and providing direct contact with stakeholders.

The following subsections delve into the different foreseen roles for each DIH component and their corresponding responsibilities. For all the different roles, a letter of commitment was requested prior to the nomination and posterior appointment having had meetings to discuss questions and requirements. 


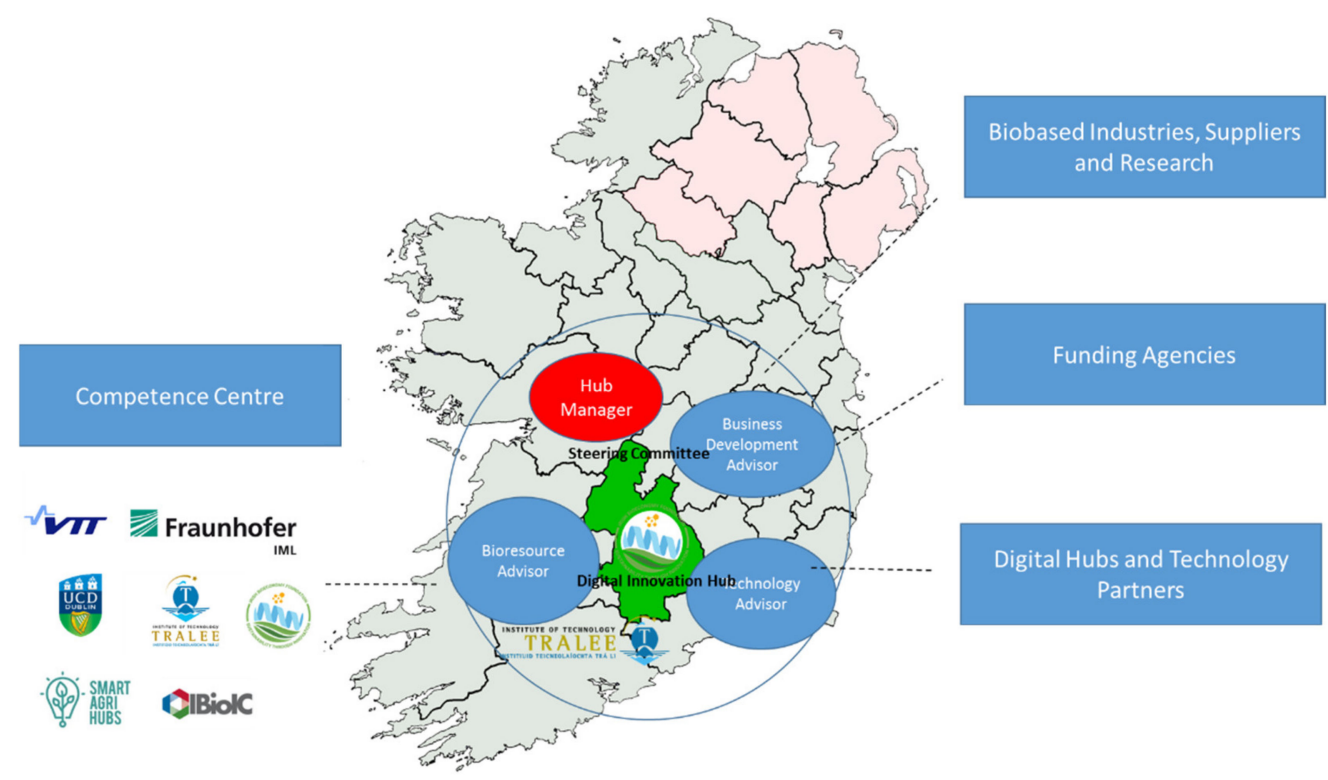

Figure 7. Irish DIH structure and how it integrates with the already existing bioeconomy ecosystem.

\subsubsection{Hub Manager}

Each DIH was assigned a hub manager who established a steering committee, to oversee the development of hub activities, liaise with regional stakeholders, deliver project activities and develop cross-national initiatives. In both case studies, the chosen hub manager was a person with a strong background in bioeconomy, a strong network of stakeholders in the region and the capability of mobilizing main actors.

According to the letter of commitment, main duties were (1) establishing a steering committee to oversee the development of Hub activities, (2) liaising with the regional stakeholders to deliver project activities and develop cross-national initiatives, (3) providing feedback on events agendas and suggesting speakers and/or participants when needed, (4) attending DIH events, (5) interacting with DIH stakeholders at the events, (6) cooperating with the regional organisation and the regional facilitator in order to ensure a smooth DIH implementation and (7) cooperating with other regions' DIHs in order to swiftly move forward in the regional development of this initiative.

\subsubsection{Steering Committee}

The main role of the steering committee was to oversee the development of hub activities. This committee included DIHs; ICT, IoT and Industry 4.0 specialists; biomass specialists and enterprise experts. The selection of the committee was conducted by the hub manager with the support of the regional organisation and the regional facilitator.

Concerning how to ensure the commitment of the committee members, different approaches were conducted (according to the duties assigned). When light duties were assigned and no final retribution was foreseen, a letter of commitment can be enough. Other cases where a more intensive work/contribution is expected could envisage hiring some members of the committee. In the case of Andalusia, only letters of commitment were asked, while in the case of south-east Ireland, a mixed approach was followed as specific, intensive contributions were needed from certain advisors.

As a rule of thumb, main duties for the members of the steering committee are (1) in cooperation with the hub manager, overseeing the development of hub activities; (2) suggesting new organizations and entities to be involved in the DIH; (3) providing feedback on events agendas and suggest speakers and/or participants when needed; (4) attending DIH events; (5) supporting regional organization and facilitator when contacting stakeholders out of their networks; (6) cooperating with the regional organization and the regional facilitator in order to ensure a smooth DIH implementation and 
(7) providing advice on (a) bioresource advisor- "the status of biomass value chains", (b) technology advisor- "the use and opportunities that ICT, IoT and Industry 4.0 strategies can bring to the region" and (c) the business development advisor- "the best approaches for business development for the different opportunities emerging from the DIH activities".

\subsubsection{Competence Centre}

The hubs developed in the ICT-BIOCHAIN project were closely related to a competence centre which helped to achieve the expected results. These competence centres provided access to the best knowledge, information and technology to promote opportunities for ICT, IoT and Industry 4.0 to be integrated into high potential biomass value chains. Moreover, the DIHs, through the competence centre, offered the best know-how on assembly and financing of biomass-supply-chain-related equipment and solutions.

As for the case studies, and after a careful analysis of the baseline situation, it was concluded that both regions did not have a one single research centre that could play this role. Accordingly, it was decided to create a network composed of local research groups. A letter of commitment was asked of the groups, stating main duties as follows: (1) working closely with the DIH hub manager and the steering committee in order to ensure a smooth and effective implementation of the DIH; (2) providing access to the best knowledge, information and technologies related to ICT, IoT and Industry 4.0 that can be integrated into high potential regional biomass value chains; (3) identifying new opportunities for improving biomass supply chains through the integration of existing and new ICT, IoT and Industry 4.0 solutions, together with stakeholders; (4) discussing and exchanging knowledge about how these technologies can be integrated within/adapted to regional biomass supply chains, together with stakeholders; (5) signing appropriate non-disclosure agreements (NDAs), if needed, in order to perform all or some of these mentioned collaborations and (6) attending DIH events.

\subsection{DIH Activities and Stakeholder Engagement}

Once established, stakeholder engagement was conducted and several activities were carried out, aiming to boost regional development.

\subsubsection{Launch and Knowledge Transfer Event}

A knowledge transfer workshop was combined with the DIH launch event in order to increase the attractiveness and, therefore, increase guest attendance. Hence, two events were organised, one in each case-study region, framed in the developed DIHs. These events saw both the launch of the two hubs, as well as the transfer of knowledge gained from the assessment of current ICT, IoT and Industry 4.0 solutions in European biomass utilisation conducted by the ICT-BIOCHAIN project. The two regional events included an introduction to the DIHs, their goals and the services and the support they provide. In each case study, this was followed by several presentations from both local and European state-of-the-art technologies that exist for the biomass sector. The aim of these events was, therefore, to disseminate these results to a wide audience in order to promote the use of ICT, IoT and Industry 4.0 solutions within the biomass sector and encourage their integration. The events were planned to facilitate networking, matchmaking and knowledge and innovation transfer between primary producers/industry; ICT, IoT and Industry 4.0 specialists; bio-based industries; etc.

The Andalusian DIH knowledge transfer workshop was divided into two sessions. The first one included a presentation about the bioeconomy status in the region; the ICT-BIOCHAIN project and the key aspects of the DIH implementation in the region, such as a presentation of all the members of the steering committee. The steering committee introduced their organisations and the benefit each kind of profile could have by participating in the hub. The second session was devoted to knowledge transfer, where both bio-resource data modelling for bioeconomy regions in Scotland and ICTs for improving the efficiency of biomass supply chains were presented, together with the technological solutions from Soltel, Wellness Telecom, Agrosap, ec2c, Integra Factory and Symbia 
Solutions. The session ended with two parallel sessions: (1) a dynamic workshop using a "World Café" approach aiming to identify needs and opportunities of collaboration between ICT and biomass-related companies, promote value chain coalitions and network development and present the DIH value proposition and (2) a space to promote local competence centre structuring. The two sessions were divided by networking sessions such as a lunch or coffee break. The total number of attendees was 57, with a well-balanced profile distribution (32 attendees represented private companies, 7 attendees represented public administrations, 5 attendees represented the Andalusian academic sector and other organisations included cooperatives, SME associations and platforms).

At the end of the workshop, participants were asked to fill out a feedback form. The first question was about rating different aspects of the event such as venue and arrangement, communication, interest in the event's content, speaker quality, networking opportunities and overall evaluation. The results showed all the aspects of the event were rated either "good" or "very good", thus, showing that, overall, the participants were highly satisfied with the organisation of the day. Participants were also asked for the number of new contacts they established on the day. The results showed that the average number of contacts was 3 (same as Irish case), with up to 12 contacts made. Moreover, participants were asked about which kind of services they would like to receive from the DIH. The votes were financing and investment support, strategic support in cooperation agreements and knowledge about regional potential for activities in the biomass sector. In addition, participants were asked about topics to be considered for further events. Main answers were related to project funding, circular bioeconomy, rural development, big data and remote sensing. Finally, participants were asked how they found out about the event. The results show that direct invitation via email was the most successful method of dissemination. This is expected because the method is more personal and, therefore, more likely to grab the attention of the stakeholder.

The Irish DIH knowledge transfer workshop was divided into three sessions. The first one included presentations and demonstrations from European examples of technologies being used in the biomass sector: an overview of the technology scoping exercise, the Agrocycle matchmaking platform and Quanturi's Haytech technology. The second session included local examples: UCD's (University College Dublin) biomass supply chain optimisation, Celignis's near-infrared biomass analysis technology and IMaR's Freshbox technology. The concluding session involved a presentation on potential funding opportunities and a workshop to determine the needs and opportunities of biomass stakeholders from technology and the DIH. The three sessions were divided by networking sessions such as lunch or coffee breaks. The final workshop session was used to encourage participants to brainstorm about problem areas in their biomass supply chain processes and come up with ideas and solutions that they could implement to rectify them. The event attracted stakeholders from multiple sectors and industries. The total number of attendees was 60 , most participants being representatives from governmental organisations or research institutions.

At the end of the workshop, participants were asked to fill out a feedback form which concerned event aspects rating. The results showed how all the aspects of the event were rated either "good" or "excellent", thus, showing that, overall, the participants were highly satisfied with the organisation of the day. Regarding the number of contacts, participants made at least one new contact, but the majority made at least three new contacts on the day, with a maximum of 6-8 new contacts. As pertains to other topics that the participants would have liked to hear about during the day, answers included the use of forest products in the bioeconomy, biorefinery examples in rural areas, development of predicting models for composition and farmer/producer engagement. Finally, participants were asked how they found out about the event and results showed again (same as in the Andalusian case) that direct invitation via email was the most successful method of dissemination.

\subsubsection{Demo Day}

A demonstration day of ICT tools for biomass value chains was planned for each region, through a field trip or on-site exhibition in which tools for supply chain enhancement were demonstrated to 
members of the newly established DIH groups, as well as other bioeconomy opportunities involving biomass. The aim of these events was to disseminate these practices in the respective regions and, therefore, promote the use of ICT, IoT and Industry 4.0 solutions within the biomass sector and encourage their integration.

The Andalusian demonstration day included visits to three sites in the province, as well as a speech from one relevant biomass actor (agri-food sector). A coach service was hired for the day to transport the participants between the three sites. The first site visit was at EMASESA-E.D.A.R El Copero (Dos Hermanas). Although EMASESA is the local public wastewater treatment company, it has implemented a co-digestion plant where it receives wastes from organisations in the surrounding areas (especially agri-food wastes such as tomato waste, olive mill waste, etc.) and conducts a co-digestion process together with the sludge. By adding agri-food waste, the co-digestion yield and overall process performance are improved. The second site visit was the Instituto de la Grasa that belongs to the Consejo Superior de Investigaciones Científicas (CSIC-Consejo Superior de Investigaciones Científicas, campus Univ. Pablo de Olavide, Dos Hermanas). It has an olive mill pilot plant that is used by companies in order to investigate potential blends. It also has an additional facility for biomass treatment and analysis. The final site visit was the olive mill cooperative Oleícola El Tejar (Marchena). Specifically, its biomass storage and treatment plant were visited. There, Cítricos del Andévalo (García Carrión Industrial Group) provided a presentation about its biomass management strategy (citrus fruits biomass). A total of 26 people attended the event, coming from different sectors and profiles, having public administration, academia and the private sector represented.

At the end of the demo day, participants were asked to fill in a feedback form. The results showed all of the event aspects were mostly rated as "very good", thus, showing that, overall, the participants were highly satisfied with the organisation of the day. About the number of contacts, four participants made up to five contacts while the rest of the participants made between two and four, with some outliers that made a bigger number. Furthermore, participants were next asked about whether they had spotted a cooperation opportunity and 10 of them answered positively. Other topics that the participants were interested in for future events include access to funding and further knowledge exchange. Finally, participants were asked how they found out about the event, with email the most voted one. This is probably since, prior to an event invitation, a "save the date" email was sent in advance.

The Irish demonstration day included three site visits on technology being used within the biomass sector and, therefore, benefiting the bioeconomy. The first site visit was at a Coillte forest. Coillte is the Irish state forestry organisation and is considered to be the most technologically advanced forestry organisation in the country. With the following two site visits being in County Limerick, Coillte selected a nearby and suitable forest to give their demonstration. The demonstration involved an overview of their "Connected Forests" system which includes a forest inventory and an earth observation programme to support strategic and tactical planning. The second site visit was to Celignis Analytical, a biomass analysis laboratory. During the visit, Celignis demonstrated their near-infrared spectroscopy rapid biomass analysis which uses custom models and proprietary software, as well as their provision of biomethane potential data for anaerobic digestion. The final site visit and technology demonstration was to BHSL Hydro. BHSL Hydro is an agro-tech company for the poultry industry and showed their remote monitoring and control systems as well as their patented Fluidised Bed Combustion Technology which converts poultry manure into heat and electricity for use on the farm. The total number of attendees was 21. Representatives were present from governmental entities as well as from companies in the technology sector, research organisations and consultancies.

At the end of the demo day, participants were asked to fill out a feedback form. The results showed all of the aspects of the event were rated either "good" or "excellent", with just one participant marking the networking opportunities as "average", thus, showing that, overall, the participants were highly satisfied with the organisation of the day. All the participants made at least one new contact, but the majority made three new contacts on the day, with a maximum of four new contacts. Other topics that 
the participants would have liked to hear about during the day included local-level opportunities, marine biorefinery technologies for macroalgae, food-waste-related technologies (e.g., sensors), farming technologies and water recovery technologies, as well as wastewater valorisation opportunities, such as a biological fuel cell technology. Finally, concerning how the participants found out about the event, email was the most voted approach. At the same time, however, several people found out about the event through various means, which shows the importance of simultaneously using several different methods for event dissemination.

\subsubsection{Business Opportunities Support}

Aside from the different events that were organised, direct actions involving stakeholders were organised to promote regional business opportunities development. Both DIHs have the following knowledge and expertise, which were made available to the different stakeholders: (1) biomass availability, (2) value chain expertise, (3) technology solutions, (4) contacts and networks and (5) funding advice.

Both DIHs used this knowledge to support potential stakeholders with relevant business ideas that brought the biomass and technology sectors together. This work was done by first identifying relevant stakeholders (thanks to the feedback forms and questionnaires provided at the events), contacting them and providing them with the necessary support. Around 60 business opportunities were promoted and supported in total for the two case studies.

Moreover, in the case of the Andalusian DIH, a set of preparatory actions targeting start-ups and SMEs were conducted. Specifically, two webinars were organised: the first one was devoted to the exchange of knowledge regarding State of the Art (SoA) ICT, IoT and Industry 4.0 solutions, while the second one was devoted to providing knowledge about how to prepare a pitch for investors.

As for the Irish DIH, any successful cross-sectorial business coalitions were again contacted in order to invite them to a regional investment day. This day involved an outline of the funding opportunities available to the stakeholders as well as personalised advice on suitable funding calls for each idea, which was passed on through one-on-one meetings with a dedicated DIH representative.

Finally, and as a direct result of the feedback gathered from stakeholders at the demo and investment days about the need of having a complete overview of all available funding related to ICT, agri-food and bioeconomy, a "funding brochure" (Figure A1, please see the Appendix A) was produced by the Irish regional partners in cooperation with the Irish government [35]. This document adds up to the information provided in the Report on Regional and EU Funding Mechanisms to exploit innovations in the Digital Biobased Economy produced in the frame of the ICT-BIOCHAIN project where European, national (Spain and Ireland) and regional (Andalusia and south-east Ireland) private and public funding opportunities are mapped. Both documents were disseminated among stakeholders in order to catalyse and support the development of the business opportunities promoted in both DIHs.

\subsection{Value Chain Coalitions and Regional Development}

The trans-disciplinary, cross-sectorial and technology transfer elements of the two developed DIHs are reflected by several aspects: (1) diverse disciplines of knowledge are integrated-ICT, IoT, Industry 4.0, agriculture, food, forestry, biotechnology, mathematical modelling and optimization, logistics, sustainability assessment methodologies and economics; (2) different biomass types are included-vegetable residues and by-products from the agri-food sector, olive-mill-related biomass and algae (Andalusia), lactose whey for the production of biochemicals/bioplastics, horticulture residues (mushroom, apple pomace, tomato pomace, potato residues) for production of biochemicals and lignocellulosic materials (straw and forestry residues) for bio-based applications (in south-east Ireland); (3) DIHs include organizations from diverse industrial sectors (sizes and types), regional administration, clusters, research centres, universities, NGOs, etc. and (4) measures taken from the innovation management paradigm were considered in the hub design to create interconnections supported on promotion of knowledge and technology transfer. 
Figures 8 and 9 summarize the eight new cross-sector interconnections in the DIHs that were created. Not only were cross-interactions created between each biomass sector, ICT, IoT and Industry 4.0, but also between biomass sectors as combinations of biomass supply chains that were also assessed in the DIHs (e.g., combination of straw and forestry residues as part of a combined lignocellulose supply chain). Hence, DIHs allowed the creation of three cross-sector interconnections by region between the biomass sector, ICT, IoT and Industry 4.0 plus one interconnection per combined biomass supply chain. These interconnections have had an impact in the day-to-day activities of the DIHs as they trigger new business model development; increase the contact with investors, companies and academia and, from a global point of view, increase the competitiveness of the private sector at a regional level and in the bio-based economy.

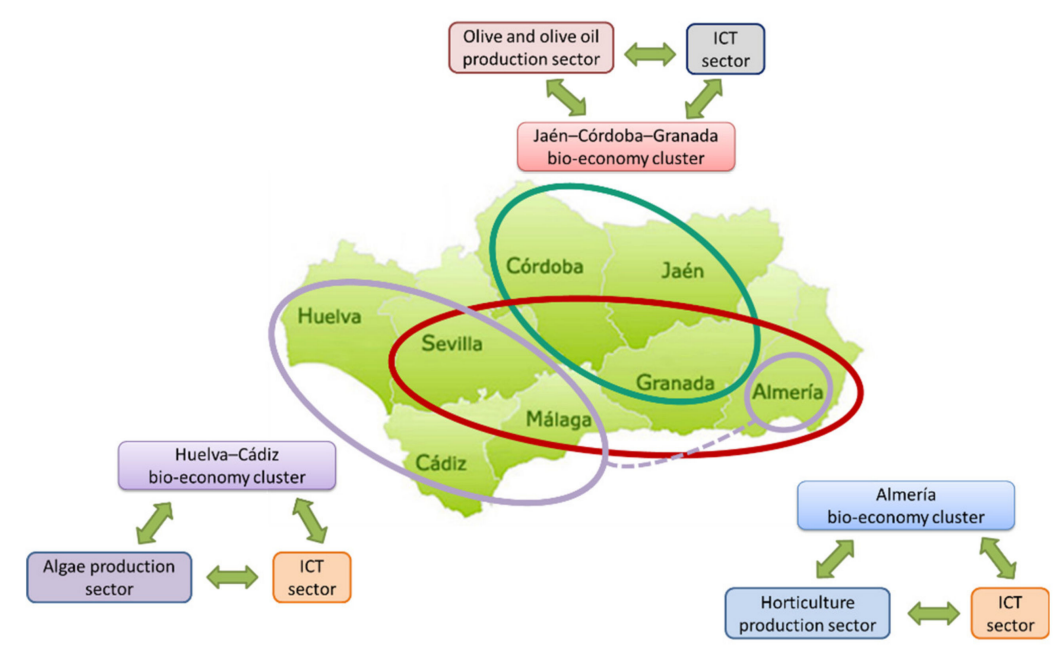

Figure 8. Cross-sector interconnections created in the frame of the DIH, Andalusia (Spain). Please note that for the sake of clarity, interconnections created by combined biomass supply chains are not depicted.

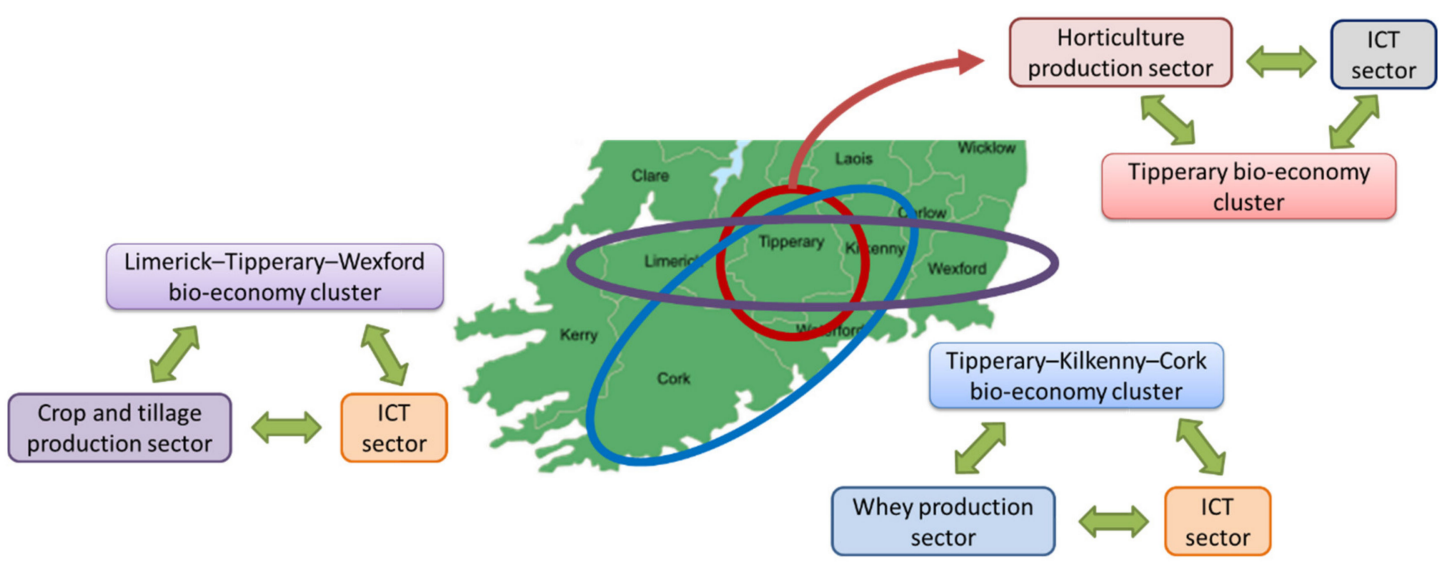

Figure 9. Cross-sector interconnections created in the frame of the DIH, south-east Ireland (Ireland). Please note that for the sake of clarity, interconnections created by combined biomass supply chains are not depicted.

\subsection{Summary of the Outcomes of the Approach}

Table 1 presents an overview of the outcomes of the approach for regional DIHs' implementation developed as a result of the ICT-BIOCHAIN project. 
Table 1. Summary of main outcomes of the proposed approach for DIHs' development.

\begin{tabular}{|c|c|}
\hline Stage/Action & Main Outcomes for the Two Case Studies \\
\hline Baseline definition & Current regional situation of ICT, IoT and Industry 4.0 adoption in biomass value chains \\
\hline $\begin{array}{l}\text { Barriers } \\
\text { identification }\end{array}$ & Barriers Mitigation Toolbox \\
\hline $\begin{array}{l}\text { DIH structure } \\
\text { definition }\end{array}$ & $\begin{array}{l}\text { Structure defined: hub manager, steering committee and competence centre. } \\
\text { This structure has been particularized for each case study }\end{array}$ \\
\hline $\begin{array}{c}\text { Stakeholder } \\
\text { engagement plan }\end{array}$ & $\begin{array}{l}\text { Four main aspects to be considered have been identified: stakeholder characterisation } \\
\text { by profiling, customized communication materials, production of key messages and } \\
\text { identification of preferred communication channels }\end{array}$ \\
\hline $\begin{array}{l}\text { DIHs activities } \\
\text { (events) and } \\
\text { stakeholder } \\
\text { engagement }\end{array}$ & $\begin{array}{l}\text { More than } 100 \text { people from different organisation profiles (private sector, public } \\
\text { administration, academia, NGOs) have been involved. Events as main tool for } \\
\text { DIHs' dynamisation }\end{array}$ \\
\hline $\begin{array}{l}\text { Value chains } \\
\text { coalitions and } \\
\text { regional } \\
\text { development }\end{array}$ & $\begin{array}{l}\text { Successful business case in Ireland: (1) cross-sectorial business coalition was formed } \\
\text { between a biomass consultancy and a technology company, (2) second successful } \\
\text { cross-sectorial business coalition was formed between a mushroom co-operative and a } \\
\text { technology research organisation, (3) third successful cross-sectorial business coalition } \\
\text { was formed between a biorefinery company and a technology research organisation. } \\
\text { Successful business case in Spain: (1) rural development consultancy company, (2) rural } \\
\text { development group was connected to a technology provider and cooperation was } \\
\text { already established with a large dairy and food company located in the geographical } \\
\text { area of the rural development group, (3) third business case arose at the demo day } \\
\text { where a technology provider spotted an opportunity after listening to the speaker's } \\
\text { presentations where they identified some of their challenges and needs-the identified } \\
\text { speaker was a wastewater treatment company. }\end{array}$ \\
\hline
\end{tabular}

\section{Discussion}

Creating local associative initiatives to promote innovation is a world-wide recognised best practise [36]. The integration of companies and universities in technology parks or techno-business incubators facilitates the configuration of a network with high potential for the generation of business opportunities and jobs which are focused on the acquisition of knowledge and the generation, transfer and commercialisation of technology. The concentration and interaction of companies and universities within the environment of a technology park usually add status and reputation to an area which individual members would fail to attain by themselves. Science and technology parks generate the ideal conditions for the necessary interaction between innovative companies and knowledge generation centres. The new orientation of innovation towards networking and shared knowledge encourages a productive network creation which can be more competitive and has greater access to cutting-edge technologies. DIHs are, however, easier to structure and get into operation; can gather interest from stakeholders belonging to different clusters, universities and technological parks at local/regional levels and have a clear focus to promote innovation and competitiveness by applying ICT solutions. Aspects related to DIH shaping and operation are presented by Hervas-Oliver et al. [37]. Specifically, their results show that DIH policy can be aimed at promoting collaborative platforms, encouraging place-based initiatives and promoting open innovation among all sorts of local/regional actors. In order to do so, the DIH program would be based on interaction, bottom-up collaboration and cluster-like functioning so as to trigger the creation of alliances that account for local/regional contextual specificities and demands, promoting the mobilization of resources to solve spatially bounded problems.

Furthermore, the Green Deal (GD) [38] is an integral part of the European Commission's strategy to implement the United Nation's 2030 Agenda and the sustainable development goals [39]. It is a new socio-economic growth strategy that aims to transform the EU into a fair and prosperous society, with a modern, resource-efficient and competitive economy, with no net emissions of greenhouse gases in 2050 and where economic growth is decoupled from resource use. "Mobilising industry for a clean 
and circular economy" is one of the major objectives of the GD [38], which includes two challenges concerning digitisation of biomass value chains. The first challenge is to ensure industrial access to raw material as a strategic security question for Europe's ambition to deliver the GD the supply of sustainable raw materials. Diversifying supply from both primary (like biomass) and secondary sources (like agri-food industrial side-streams, by-products and waste) is considered by the EC, therefore, one of the pre-requisites to make this transition happen. The second important challenge is to build awareness and engagement in the agri-food sector to put sustainability as their first priority; the EC will consider measures to improve resource efficiency and circular economy performance of this sector itself, from broadband networks to data centres and ICT devices, as digital technologies are a critical enabler for attaining the sustainability goals of the GD in many different sectors. The Commission is committed to exploring measures to ensure that digital technologies, such as artificial intelligence, 5G, cloud and edge computing and the Internet of things (Industry 4.0 approaches being a part of it), can accelerate and maximise the impact of policies to deal with climate change and protect the environment [38].

DIHs, as described in this article, can be pointed out as one of those industrial mobilising structures showing the capacity to accelerate and maximise the impact of digital technologies on the implementation of the GD by 2050. As has already been described, DIHs characterised in this article have been designed to address ICT sector acceleration for attaining the sustainability goals of the GD in many different sectors. By focusing on digitisation of key regional biomass value chain supplies, effectively engaging and activating networking and offering value chain building and support to all the key stakeholders involved in the agri-food sector, a contribution to sustainability acceleration can be reached, but only if DIHs of this type are fed and improved consistently by their private and public stakeholder members. In practical terms, the implementation of the herein presented DIH approach would allow one to make the most out of regional bioresources, especially in those regions where these are scattered (rural and coastal areas) and opportunities are lost since not enough volume can be achieved because of inefficient or complex logistics. This would have a direct impact in regional/local development, boosting the adoption of bioeconomy.

The design process of the DIHs in the two case studies showed that, although both regions had the same goal (boosting biomass valorisation in the regional bioeconomy), the way DIHs have been designed slightly differ. This is due to the fact that the two case studies have different starting points and, in order to maximise the impact of the DIHs at the regional level, it was decided that integrating the DIHs in the local context was of utmost relevance. So, results and experience achieved show that DIH background should be always considered through early identification of existing local/regional DIHs and/or clusters, actions and public administrations acting as an umbrella and/or potential collaborators in similar areas, in order to establish, in the beginning, stable formal and operative connections with them.

Ensuring multi-stakeholder engagement and mobilisation is key for the creation of an innovation ecosystem as reported in the LIFT Project (LIFT_-Unleash the potential of CSAs results to contribute to sustainable and competitive Bio-Based Industries in Europe) Fact Sheet number 3 [40]. The LIFT Project is a European project where a total of 35 coordination and support action projects for a bio-based economy were mapped, their good practices analysed and common recommendations obtained and disseminated to be taken into account for future actions. Concerning DIH stakeholder engagement, it is very important to consider that each of them has different profiles, requiring different communication approaches (especially key messages). Furthermore, General Data Protection Regulation (GPDR) issues needed to be considered and implemented when contacting them. To stimulate stakeholders' participation in the $\mathrm{DIH}$, customised materials were produced stating the specific benefits of joining the DIHs for each stakeholder profile. These materials were produced in the local language, a key aspect in the communication strategy. The design of impactful awareness and communication strategies, tailoring the message to the different target audiences, has been reported as well in the LIFT Project Fact Sheet number 1 [41]. This customisation approach using innovative channels like large-scale 
events or workshops, and tools like videos, dissemination materials, contests and social media just-on time-posts were used recurrently in the communications strategy presented in the methodology.

Finally, the success of a region in terms of knowledge transfer depends on many factors, including its entrepreneurial initiative, the strategy of its universities and its public development policies. However, REUNE (a good practices online manual) best practice guidelines for academy and industry collaboration [42] showed that a key aspect for effective technology transfer consists of "generating transfer catalysts". The world's most advanced regions in this respect have encouraged and facilitated the creation of organisations and entities which act as effective catalysts in the dynamisation of collaboration between industries and universities for the development of innovation systems which are characterised by their strength and high levels of efficiency. DIHs must contribute to effective technology transfer by embracing this role. This aspect has been addressed in the investigations conducted through the participation of stakeholders in a technology transfer day.

\section{Conclusions}

Two DIHs were developed in two European regions that acted as case studies, aiming to bring together leading experts and support networks, in order to trigger and support opportunities for ICT, IoT and Industry 4.0 applications for the efficiency of high potential biomass supply chains. DIH activities have, therefore, a strong impact at the regional level concerning the adoption and transition to a sustainable bio-based approach and could be pointed out as another successful tool in the frame of open innovation approaches and strategies. So far, more than 100 people from different organisation profiles (private sector, public administration, academia, NGOs) have been involved in the DIHs' activities, benefiting from the promoted knowledge exchange and innovation and business opportunities' development.

The main lessons learned from these experiences are (1) to maximise the impact of the DIHs at the regional level, integrating the DIHs in the local context of digitisation actions and policies, is of utmost relevance; (2) understanding the needs of the industries participating is very relevant to become an effective bio-based economy DIH; (3) a demonstration day where the industry (rather than academia or technology providers) can discuss the technologies that they have integrated, and inform stakeholders about the way in which this technology has improved efficiency or added value to their process has a big impact and (4) communication and dissemination plans, as well as a well-formed DIH service definition, are important.

On top of these, it is possible to draw some additional conclusions related to DIHs' design and main actions planned and conducted when implementing the DIHs. It is important to highlight how the followed methodology for the establishment of DIHs in the two MDRs with backgrounds and future goals as different as south-east Ireland and Andalusia can be applied in both regions. Only by adapting several foundational structures but maintaining the core process equally can it be concluded that these findings highlight the possibility to replicate DIH formation in any region working on bioeconomy.

As for the regional knowledge transfer days, there were several learnings, as well. (1) Stakeholders acknowledged wanting more time to continue discussing ideas amongst each other. For this reason, it is recommended to have the workshop earlier on in the day, so that participants can continue discussions during the lunch and the remaining coffee breaks. (2) For the Andalusian event, the participants' name tags included not only the person's name, but also their organisation, as well as different coloured dots corresponding to different profiles, i.e., whether they were from the biomass sector, IT sector, etc. This was not done during the Irish event, and feedback showed that the participants would have liked to see that information there since it facilitates networking. (3) For the local competence centre, a parallel session between research groups and project partners acting as an international competence centre of the DIH was organized. In this case, the success rate was moderated due to low local research groups' participation and the difficulties found in guiding the conversations. Hence, it is proposed that the selection of a convenient date and a much more structured approach should be implemented in similar sessions. 
In addition, throughout the planning of the two regional demonstration days, lessons to be taken into account to guarantee maximum success have been learned; they are that (1) it is recommended to ensure that the demonstrations are varied so as to attract people from different sectors and, therefore, engage various industries with the bioeconomy and (2) to continue distributing the questionnaires at each event will increase the number of responses and potentially vary the audience profile, making it possible to obtain new insights into opportunities for digitised bio-based economy value chain building.

These lessons learned could be applied to workshops aiming for intersectoral collaboration and for technology transfer and innovation promotion, not necessarily framed in a regional DIH action plan. Moreover, other knowledge area workshops with these same objectives could benefit, as well, from the integration of these lessons learned when shaping them (e.g., digitisation of agri-food sector or lean manufacturing adoption by textile sector).

Further research activities are foreseen in order to enlarge the DIH value chain coverage, enhancing this way the impact at a regional level. Specifically, the set of biomasses considered in the DIHs will be enlarged in the short-medium term, contributing as well to the sustainability of bioproduct markets. In the case of Andalusia, forestry and livestock will be considered the next target, while in the case of south-east Ireland, algae (marine and seaweed) and organic waste are going to be the next focus. In addition, limitations from the work presented herein can be addressed through future research studies along value-chain-specialised DIH formation. One of the drawbacks of these types of studies lies in the small number of DIHs currently existent and their relatively heterogeneous geographic distribution. A recommendation for further investigations in the field of DIH design and development may address not only DIHs' perspectives, but analyse SMEs' perceptions of the services that are offered to corroborate and expand the findings presented here, for example, considering a larger scale of DIHs differentiating per structure, sector and technology, examining also the partners' view (e.g., large firms and universities).

Briefly, conclusions and lessons learned from the experiences of DIH establishment are summarised below.

- Firstly, in order to maximise the impact of the DIHs at a regional level, integrating the DIHs in the local context of digitization actions and policies is of utmost relevance.

- Secondly, understanding the needs of the industries participating is very relevant to become an effective bio-based economy DIH.

- Thirdly, to create a higher impact for the demonstration day, industry, rather than academia or technology providers, must discuss the technologies that they have integrated, and inform stakeholders about the way in which this technology has improved efficiency or added value to their processes.

- Finally, the importance of communication and dissemination plans, as well as a well-formed DIH service definition, is crucial when establishing this type of structure to maximise the mutual benefit and collaborations.

Author Contributions: M.M.A., G.d.l.V.N., M.N.F., D.P.R., J.G., J.A., H.M., P.D.; J.A.U., M.N.P.-C., M.S.C.M., A.J.G.M., F.G.M.; methodology, M.M.A., G.d.I.V.N., M.N.F., D.P.R., J.G., J.A., H.M., P.D.; J.A.U., M.N.P.-C., M.S.C.M., A.J.G.M., F.G.M.; investigation, M.M.A., G.d.I.V.N., M.N.F., D.P.R., J.G., J.A., H.M., P.D.; J.A.U., M.N.P.-C., M.S.C.M., A.J.G.M., F.G.M.; writing-review and editing, M.M.A., G.d.I.V.N., M.N.F., D.P.R., J.G., J.A., H.M., P.D.; J.A.U., M.N.P.-C., M.S.C.M., A.J.G.M., F.G.M. All authors have read and agreed to the published version of the manuscript.

Funding: This research was funded by the Bio-based Industries Joint Undertaking under the European Union's Horizon 2020 research and innovation programme under grant agreement No 792221.

Acknowledgments: Authors would like to acknowledge the support from ICT-BIOCHAIN project partners: Sustainable Innovations Europe S.L., Teknologian tutkimuskeskus VTT Oy, Industrial Biotechnology Innovation Centre ("IBioIC")-University of Strathclyde and Fraunhofer gesellschaft zur foerderung der angewandten forschung E.V.-IML.

Conflicts of Interest: The authors declare no conflict of interest. The funders had no role in the design of the study; in the collection, analyses, or interpretation of data; in the writing of the manuscript or in the decision to publish the results. 
Appendix A

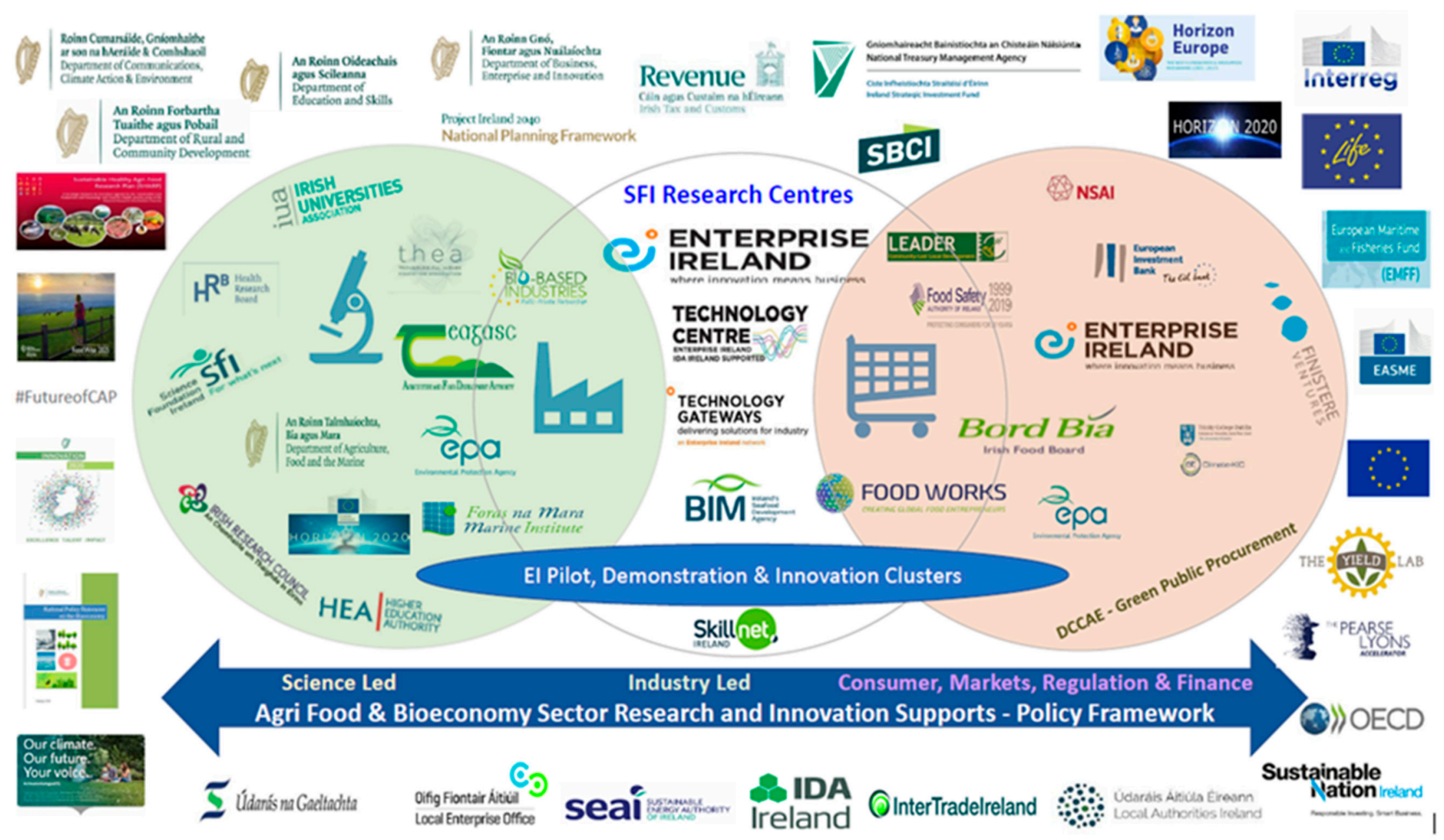

Figure A1. Map of funding sources available for the Irish DIH. 


\section{References}

1. Fritsche, U.; Brunori, G.; Chiaramonti, D.; Galanakis, C.M.; Hellweg, S.; Matthews, R.; Panoutsou, C. Future Transitions for the Bioeconomy towards Sustainable Development and a Climate-Neutral Economy—Knowledge Synthesis Final Report. Knowledge Synthesis and Foresight Work Package 1-Network of Experts; Publications Office of the European Union: Luxembourg, 2020.

2. USDA Foreign Agricultural Service. EU Bio-Based Economy and Its Inputs; USDA Foreign Agricultural Service: Washington, DC, USA, 2015.

3. BIO-TIC Project. The Bioeconomy Enabled: A Roadmap to A Thriving Industrial Biotechnology Sector in Europe. 2015. Available online: http://www.industrialbiotech-europe.eu/wp-content/uploads/2015/08/BIO-T IC-roadmap.pdf (accessed on 19 May 2020).

4. Flak, J. Technologies for Sustainable Biomass Supply-Overview of Market Offering. Agronomy 2020, 10, 798. [CrossRef]

5. Vlachokostas, C. Closing the Loop between Energy Production and Waste Management: A Conceptual Approach towards Sustainable Development. Sustainability 2020, 12, 5995. [CrossRef]

6. Rouse, M. IoT Agenda. 2019. Available online: https://internetofthingsagenda.techtarget.com/definition/Inte rnet-of-Things-IoT (accessed on 19 May 2020).

7. European Commission. Digitising European Industry-Reaping the Full Benefits of a Digital Single Market COM (2016) 180 Final. 19 April 2016. Available online: https:/eur-lex.europa.eu/legal-content/EN/TXT/?ur $\mathrm{i}=$ CELEX:52016DC0180 (accessed on 19 May 2020).

8. European Commission. Digital Innovation Hubs (DIHs) in Europe. Available online: https://ec.europa.eu/d igital-single-market/en/digital-innovation-hubs (accessed on 19 May 2020).

9. European Commission. Digital Innovation Hubs Catalogue. Available online: https://s3platform.jrc.ec.euro pa.eu/digital-innovation-hubs-tool (accessed on 19 May 2020).

10. DIHELP Project, DIH Academy. Available online: https://dihelp.eu/dih-academy/ (accessed on 20 May 2020).

11. European Commission. Digital Innovation Hubs-Smart Specialisation Platform. Available online: https: //s3platform.jrc.ec.europa.eu/digital-innovation-hubs (accessed on 20 May 2020).

12. Crupi, A.; Del Sarto, N.; Di Minin, A.; Gregori, G.L.; Lepore, D.; Marinelli, L.; Spigarelli, F. The digital transformation of SMEs-A new knowledge broker called the digital innovation hub. J. Knowl. Manag. 2020, 24, 1263-1288. [CrossRef]

13. European Commission. FOCUS Project-Cordis Website. Available online: https://cordis.europa.eu/project/i d/604286/es (accessed on 20 May 2020).

14. European Commission. Indisputable Key-Cordis Website. Available online: https://cordis.europa.eu/proje ct/id/034732/en (accessed on 20 May 2020).

15. Åkerman, M.; Fast-Berglund, A.; Halvordsson, E.; Stahre, J. Modularized assembly system: A digital innovation hub for the Swedish Smart Industry. Manuf. Lett. 2018, 15, 143-146. [CrossRef]

16. Woo, H.; Acuna, M.; Cho, S.; Park, J. Park Assessment Techniques in Forest Biomass along the Timber Supply Chain. Forests 2019, 10, 1018. [CrossRef]

17. Picchio, R.; Proto, A.R.; Civitarese, V.; Di Marzio, N.; Latterini, F. Recent Contributions of Some Fields of the Electronics in Development of Forest Operations Technologies. Electronics 2019, 8, 1465. [CrossRef]

18. Rissola, G.; Sorvik, J. Digital Innovation Hubs in Smart Specialisation Strategies; Publications Office of the European Union: Luxemburg, 2018.

19. Butter, M.; Goetheer, A. Digital Innovation Hubs Catalogue-Inception Report; TNO: The Hague, The Netherlands, 2017; Available online: https://ec.europa.eu/futurium/en/system/files/ged/presentation_of_the_foreseen_digi tal_innovation_hub_catalogue_tno.pdf (accessed on 21 May 2020).

20. European Commission. Commission Selects 6 "Model Regions" to Lead the Way toward a Sustainable Chemical Industry. 26 January 2016. Available online: https://ec.europa.eu/growth/content/commission-sel ects-6-model-regions-lead-way-toward-sustainable-chemical-industry-0_en (accessed on 21 May 2020).

21. Pyka, A. Dedicated innovation systems to support the transformation towards sustainability: Creating income opportunities and employment in the knowledge-based digital bioeconomy. J. Open Innov. Technol. Mark. Complex. 2017, 3, 1-18. [CrossRef] 
22. Hervas-Oliver, J.-L.; Estelles-Miguel, S.; Mallol-Gasch, G.; Boix-Palomero, J. A place-based policy for promoting Industry 4.0: The case of the Castellon ceramic tile district. Eur. Plan. Stud. 2019, 27, 1838-1856. [CrossRef]

23. European Commission. Deliverable 1.1. Assessment of the Current ICT, IoT, and Industry 4.0 Solutions in European Biomass Utilization, ICT-BIOCHAIN. 26 February 2019. Available online: https://ictbiochain.eu/wp-content/uploads/2020/01/D1.1-Assessment-of-the-current-ICT-IoT-and-Industr y-4.0-solutions-in-European-biomass-ut.pdf (accessed on 13 October 2020).

24. European Commission. Deliverable 3.3. Validation Report of the Platform Prototype per each Region-Specific Data Model, ICT-BIOCHAIN. 29 May 2020. Available online: https://ictbiochain.eu/wp-content/uploads/ 2020/09/Deliverable-3.3-Validation-report-of-the-platform-prototype-per-each-region-specific-data.pdf (accessed on 13 October 2020).

25. European Commission. Deliverable 2.1 Regional Base Definition Report, ICT-BIOCHAIN. 31 August 2018. Available online: https:/ictbiochain.eu/wp-content/uploads/2020/01/D2.1-Regional-base-definition-report.p df (accessed on 13 October 2020).

26. ICT-BIOCHAIN Project Website. ICT-BIOCHAIN Project. Available online: https://ictbiochain.eu/ (accessed on 21 May 2020).

27. BioÉire-A Bioeconomy for Ireland: The Irish Bioeconomy-Definition, Structure, and Situational Analysis. 2017. Available online: https://www.teagasc.ie/media/website/publications/2017/WP1-Deliverable---Final-J an-2017.pdf (accessed on 21 May 2020).

28. Consejería de Economía, Conocimiento, Empresas y Universidad. Estrategia Industrial de Andalucía 2020. Available online: http://estrategiaindustrialdeandalucia.org/wp-content/uploads/2017/01/6c1114_3a6891ea30 8141ccbf4471f3655d9e83.pdf (accessed on 19 May 2020).

29. Biobased Industries Consortium, Bioeconomy Regions in Europe. 16 November 2017. Available online: https://biconsortium.eu/sites/biconsortium.eu/files/publications/BIC_GA_Brochure_Bioeconomy_regions _in_Europe_Nov_2017.pdf (accessed on 19 May 2020).

30. Banias, G.; Achillas, C.; Vlachokostas, C.; Moussiopoulos, N.; Stefanou, M. Environmental impacts in the life cycle of olive oil: A literature review. J. Sci. Food Agric. 2017, 97, 1686-1697. [CrossRef] [PubMed]

31. CIRCE; PNO Innovation; CEFIC. Andalusia as a Model Demonstrator. September 2016. Available online: http://www.bioeconomiaandalucia.es/documents/1056091/1056684/IRA+Andalusia/d55a2a1a-98f3419e-845a-d2ce5c88ea75?version=1.0 (accessed on 19 May 2020).

32. Consejería de Agricultura, Ganadería, Pesca y Desarrollo Sostenible. Estrategia Andaluza de Bioeconomía Circular-Andalusian Strategy for Circular Bioeconomy. 27 November 2018. Available online: http://www.bioeconomiaandalucia.es/documentos-y-publicaciones-de-interes?p_p_id=110_INSTANC E_9zRjmP5st3q\&p_p_lifecycle=0\&p_p_state=normal\&p_p_mode=view\&p_p_col_id=column-1\&p_p_ col_count=1\&_110_INSTANCE_9zRjmP5sst3q_struts_action=\%2Fdocument_library_displ (accessed on 19 May 2020).

33. European Commission. Digital Innovation Hubs Catalogue-Ireland. Available online: https://s3platform.j rc.ec.europa.eu/documents/20182/318091/Ireland.pdf/0517792d-542f-4327-a52f-7f992ed9db65 (accessed on 19 May 2020).

34. European Commission. Digital Innovation Hubs Catalogue-Spain. Available online: https://s3platform.j rc.ec.europa.eu/documents/20182/318091/Spain.pdf/4b96700e-157b-4c6a-bb77-0b9398669516 (accessed on 19 May 2020).

35. Irish Bioeconomy Foundation-Government of Ireland. Bioeconomy Funding Opportunities. 2020. Available online: https://bioeconomyfoundation.com/ibf-resources/funding-opportunities/ (accessed on 21 May 2020).

36. Reune. Good Practices Manual for Academy \& Industry Cooperation 2012. Chapter 9-Networks, Clusters and Technology Parks. 2012. Available online: http://www.reune.corporaciontecnologica.com/en/redes-clus teres-parques-tecnologicos/\#.XviXrTh7nIU (accessed on 29 June 2020).

37. Hervas-Oliver, J.-L.; Gonzalez-Alcaide, G.; Rojas-Alvarado, R.; Monto-Mompo, S. Emerging regional innovation policies for industry 4.0: Analyzing the digital innovation hub program in European regions. Compet. Rev. 2020. [CrossRef] 
38. European Commission. The European Green Deal. Communication from the Commission to the European Parliament, the European Council, the Council, the European Economic and Social Committee and the Committee of the regions. Brussels, 11.12.2019 COM (2019) 640 Final, Brussels. 11 December 2019. Available online: https://ec.europa.eu/info/sites/info/files/european-green-deal-communication_en.pdf (accessed on 29 June 2020).

39. United Nations. Sustainable Development Goals Knowledge Platform. Available online: https://sustainabl edevelopment.un.org/post2015/transformingourworld (accessed on 29 June 2020).

40. European Bioeconomy Powered by WWW.LIFT-BBI.EU, Recommendations from Factsheet 3. Stakeholders Engagement and Co-Creation. 2020. Available online: https://www.bioeconomy-library.eu/wp-content/upl oads/2020/03/03_LIFT_Factsheets_engagement.pdf (accessed on 21 May 2020).

41. European Bioeconomy Powered by WWW.LIFT-BBI.EU, Recommendations from Factsheet 1 . Awareness Raising and Communication. 2020. Available online: https://www.bioeconomy-library.eu/wp-content/uploa ds/2020/03/01_LIFT_FactSheets_awareness.pdf (accessed on 21 May 2020).

42. Reune. Good Practices Manual for Academy \& Industry Cooperation. Chapter 2-Knowledge Transfer between University and Business. 2012. Available online: http://www.reune.corporaciontecnologica.com/en/ transferencia-conocimiento-universidad-empresa/\#.XviWKzh7nIU (accessed on 29 June 2020).

Publisher's Note: MDPI stays neutral with regard to jurisdictional claims in published maps and institutional affiliations.

(C) 2020 by the authors. Licensee MDPI, Basel, Switzerland. This article is an open access article distributed under the terms and conditions of the Creative Commons Attribution (CC BY) license (http://creativecommons.org/licenses/by/4.0/). 